\title{
Olanzapine (Zyprexa): increased incidence of cerebrovascular events in dementia trials
}

Reason for posting: Secondgeneration antipsychotic drugs, which are felt to have fewer extrapyramidal adverse effects than the first-generation drugs, ${ }^{1}$ are sometimes used to control behavioural disturbances in elderly patients with dementia. However, similar to warnings issued in the last 2 years about risperidone and associations with hyperglycemia and cerebrovascular events, ${ }^{2}$ a warning was recently issued for another secondgeneration drug, olanzapine. ${ }^{3}$

The drug: Olanzapine is an antipsychotic agent with a novel mechanism of action. The US Food and Drug Administration recently issued a warning about an increased incidence of hyperglycemia and diabetes among patients taking the drug. ${ }^{3}$ In a separate letter to physicians, Eli Lilly Canada also recently reported some summary data on cerebrovascular event rates in 5 placebo-controlled trials of olanzapine in elderly patients (ages not specified) who had dementia (including Alzheimer's, vascular dementia and mixed dementia) (Table 1). ${ }^{4}$ According to information supplied by the manufacturer, only 2 of the 5 studies have been published in full (Table 1). The duration of the published trials was between 6 and 10 weeks, with doses of the drug ranging from 1 to $15 \mathrm{mg}$. Overall, the relative risk of a cerebrovascular event among patients taking olanzapine in the 5 trials was 3.1 (95\% confidence interval [CI] $0.7-$ 13.5) and the absolute increased risk was $0.9 \%$. The rates of cे cerebrovascular events were similar to those reported for risperidone. ${ }^{2}$

What to do: The behavioural disturbances associated with dementia are distressing for caregivers and patients alike. Before

Table 1: Incidence of cerebrovascular events among elderly patients with dementia in placebo-controlled trials of olanzapine ${ }^{4}$

Group; \% (and no.) of patients with adverse cerebrovascular event

\begin{tabular}{|c|c|c|}
\hline Study no. & Olanzipine & Placebo \\
\hline HGAO & $0 \quad(0 / 118)$ & $0.8(1 / 118)$ \\
\hline HGEU* & $0.6 \quad(1 / 159)$ & $0 \quad(0 / 47)$ \\
\hline HGGU & $2.5 \quad(5 / 204)$ & $0 \quad(0 / 94)$ \\
\hline HGIC & $2.8 \quad(5 / 177)$ & $1.1(1 / 90)$ \\
\hline HGIV† & $0.8 \quad(4 / 520)$ & $0 \quad(0 / 129)$ \\
\hline All & $1.3(15 / 1178)$ & $0.4(2 / 478)$ \\
\hline
\end{tabular}

*Street et al. Olanzapine treatment of psychotic and behavioral symptoms in patients with Alzheimer disease in nursing care facilities: a double-blind, randomized, placebo-controlled trial. The HGEU Study Group. Arch Gen Psychiatry 2000;57:968-76.

†De Deyn PP, et al. Olanzapine versus placebo in the treatment of psychosis with or without associated behavioral disturbances in patients with Alzheimer's disease. Int J Geriatr Psychiatry 2004;19:115-26.

prescribing antipsychotic medications, physicians should consider nondrug options such as education of caregivers about the behavioural disturbances and assisting them in obtaining increased home care or placement in long-term care facilities with special floors for patients with dementia-related behavioural problems. If medications are considered necessary, they should be prescribed at as low a dose as possible. Olanzapine is not licensed for use in elderly patients with dementia. Patients taking the drug should be monitored for hyperglycemia, and patients and caregivers should be informed of possible cerebrovascular risks, risks that may apply to all second-generation antipsychotic drugs.

Eric Wooltorton

CMAJ

\section{References}

1. Choice of an antipsychotic. Med Letter 2003;45:102-4.

2. Wooltorton E. Risperidone (Risperdal): increased rate of cerebrovascular events in dementia trials. CMA7 2004;167(11): 1269-70.

3. 2004 safety alert: Zyprexa (olanzapine). Washington: US Food and Drug Administration; 2004 Mar 1. Available: www.fda.gov/medwatch/SAFETY/2004 /zyprexa.htm (accessed 2004 Apr 1).

4. Olanzapine (Zyprexa) and cerebrovascular adverse events in placebo-controlled elderly dementia trials [Dear Healthcare Professional Letter]. Toronto: Elli Lilly Inc.; 2004 Mar 10. Available: www.hc-sc .gc.ca/hpfb-dgpsa/tpd-dpt/zyprexa_hpc _e.pdf (accessed 2004 Apr 1).

\section{Canadian Adverse Reaction Newsletter Bulletin canadien des effets indésirables}

To receive the Newsletter and health product Advisories by email, join Health Canada's Health_Prod_Info mailing list.

Go to $w w w . h c-s c . g c . c a / h p f b-d g p s a$ ltpd-dpt/subscribe_e.html.

Inscrivez-vous à la liste

Info_Prod_Santé de Santé Canada pour recevoir par courriel le Bulletin et les Avis au sujet des produits de santé. Rendez-vous à l'adresse www.hc-sc.gc.calhpfb-dgpsaltpd-dpt /subscribe f.html.

Report adverse reactions toll free to Health Canada • Signaler sans frais des effets indésirables à Santé Canada

Tel./Tél. : 866 234-2345

Fax/Téléc. : 866 678-6789

Email/Courriel: cadrmp@hc-sc.gc.ca

Health Santé Canadä 